\title{
Expression Quantitative Trait Locus
}

National Cancer Institute

\section{Source}

National Cancer Institute. Expression Quantitative Trait Locus. NCI Thesaurus. Code C113415.

A stretch of DNA at a particular chromosomal location that is able to regulate the expression of a specific mRNA or protein. 